
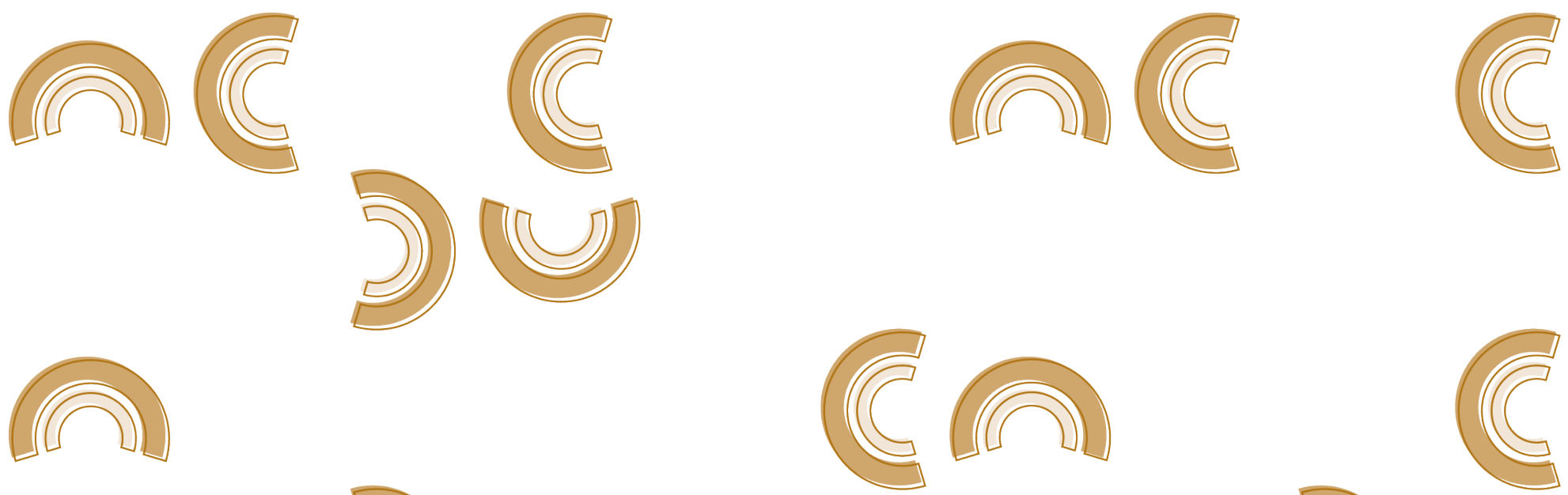

DOSSIÊ TEATRO, MEMÓRIA E TECNOLOGIA

\title{
A FOTOGRAFIA E UMA CERTA MEMÓRIA DO TEATRO
}

PHOTOGRAPHY AND A CERTAIN

MEMORY OF THE THEATER

\section{Filipe Figueiredo}

Centro de Estudos de Teatro da Faculdade de Letras da Universidade de Lisboa.

E-mail: ffigueiredo2005@gmail.com 


\section{RESUMO}

A efemeridade do teatro constitui desde sempre um permanente desafio à construção da sua memória e facilmente se compreende o recurso à fotografia, desde as primeiras décadas da sua existência, na segunda metade do século XIX, a fim de combater o seu desvanecimento. Este tipo de imagem passou, assim, a condicionar o acesso do público ao teatro e foi responsável pelo moldar de diversos conceitos da prática teatral ao longo das décadas seguintes. Em pleno século XxI, e em período de clara afirmação da cultura visual, é já impossível que a fotografia não tenha contaminado com a sua carga viral um espaço que lhe está tão próximo, desde as suas origens, na exploração da pose e da representação.

Contudo, permanece ainda hoje numa certa penumbra a compreensão do estatuto da fotografia neste contexto por parte dos seus principais operadores, seja do ponto de vista do produtor, seja daquele do observador. Se o registo fotográfico do teatro é inquestionável, falta conhecer os detalhes dessa prática e aferir a consciência que os seus agentes têm do alcance da mesma e, sobretudo, avaliar a fotografia na dupla condição de documento e monumento.

Pretende-se assim, no presente artigo, reconhecer o território disciplinar da fotografia de teatro, como um espaço autónomo de convergência tanto do olhar fotográfico quanto teatral e explorar as suas possibilidades de relacionamento e diferentes tipos de abordagem.

Palavras-chave: Fotografia de Teatro. Representação. Memória. 


\section{ABSTRACT}

Theatre ephemeral condition has always been a permanent challenge to the construction of its memory, and it is quite understandable the use of photography since the first decades of its existence in the second half of the nineteenth century in order to combat its fading. This type of image has thus conditioned the access of the public to the theatre and was responsible for shaping various concepts of theatrical practice over the following decades. In the 21st century, and in a period of clear affirmation of visual culture, it is already impossible that photography has not contaminated with its viral load a space that is so close to it, from its origins, in the exploration of pose and representation.

However, the understanding of the status of photography in this context by its main operators, whether from the producer point of view or from that of the observer, remains in a certain twilight. If the photographic record of the theatre is unquestionable, it is necessary to know the details of this practice and to check the awareness that its agents have of the reach of the same and, above all, to evaluate the photograph in the double condition of document and monument.

This article aims to recognize the disciplinary territory of theatre photography as an autonomous space for the convergence of both the photographic and theatrical gaze and to explore their possibilities of relationship and different kinds of approach.

Keywords: Theatre Photography. Representation. Memory. 


\section{AUTOR}

Filipe Figueiredo é investigador do Centro de Estudos de Teatro (FLUL), onde coordena a Linha de Investigação Teatro e Imagem. Desenvolveu estudos de mestrado em História da Arte (FCHS/UNL) com incidência na obra de Domingos Alvão e na fotografia portuguesa na primeira metade do século Xx. Integrou o projeto opsis - Base Iconográfica de Teatro em Portugal (2008-10) (CET/ FLUL) e tem colaborado em diversas iniciativas e projetos no cruzamento dos estudos de imagem com os estudos teatrais e performativos e de pesquisa e análise iconográfica. Doutorado em Estudos Artísticos (2016), com uma tese dedicada aos modelos e práticas da fotografia de teatro em Portugal - $\mathbf{0}$ Insustentável Desejo da Memória (1868-1974). (bolseiro FCT) -é, actualmente, investigador responsável, com Cosimo Chiarelli, do projeto PERPHOTO Dramaturgias do Olhar. Cruzamentos entre Fotografia e Teatro no Contexto Português e Internacional (PTDC/ART-PER/31693/2017). É professor auxiliar no IADE - Universidade Europeia. Recentemente, participou na curadoria das exposições Amélia, dedicada à relação de Amélia Rey Colaço com a fotografia (TNDM II, 2018) e José Marques - fotógrafo em cena (TNDM II, 2019), e desenvolve actividade como fotógrafo, nomeadamente fotografia de cena. 


\section{AUTHOR}

Filipe Figueiredo is a researcher at the Centre for Theatre Studies (CET/FLUL) where he coordinates the Theatre and Image Research Line. His Master's in Art History (FCHS/ UNL) focused on the work of Domingos Alvão and Portuguese Photography in the first half of the twentieth century. He has been a member of the opsis project - The Iconographic Theatre Database in Portugal (2008-10) (CET/FLUL) and has collaborated in several initiatives and projects in the cross-study of image with theatre and performance studies, as well as iconographic research and analysis. He holds a PhD in Artistic Studies (2016), his thesis being dedicated to the study of the models and practices of theatre photography in Portugal - O Insustentável Desejo da Memória (1868-1974) [The Unbearable Desire of Memory (1868-1974)] (scholarship FCT). Filipe is currently Principal Researcher, along with Cosimo Chiarelli, for the project PERPHOTO - Performing the Gaze: Crossings Between Photography and Theatre in Portuguese and International Context (PTDC/ART-PER/31693/2017). He has been an assistant professor at ESTAL Lisbon School of Technology and Arts (2002-2019) and is an assistant professor at IADE - the European University. Recently, he was co-curator of the exhibitions Amélia, on Amélia Rey Colaço's relationship with photography (TNDM II, 2018) and José Marques - photographer on stage (TNDM II, 2019), and develops photographic activity, mainly as stage photographer. 


\section{PARA UMA ONTOLOGIA DA FOTOGRAFIA DE TEATRO}

The first myth to dispel about 'theory' is the idea that we can do without it. There is no untheoretical way to see photography. While some people may think of theory as the work of reading difficult essays by European intellectuals, all practices presuppose a theory. (BATE 2009: 14)

Desde as primeiras décadas da sua existência, as fotografias condicionaram o acesso do público ao teatro e são responsáveis pelo moldar de diversos conceitos da prática teatral. Em pleno século XXI, e em período de clara afirmação da cultura visual, é já impossível que a fotografia não tenha contaminado com a sua carga viral um espaço que lhe está tão próximo, desde as suas origens, na exploração da pose e da representação.

Contudo, permanece ainda hoje numa certa penumbra a compreensão do estatuto da fotografia neste contexto por parte dos seus principais operadores, seja do ponto de vista do produtor, seja daquele do observador.

Com um olhar pertinente, em 2002, a fotógrafa Susana Paiva constatava que a fotografia sobre teatro, pelo menos no contexto português, continuava a "cumprir, única e exclusivamente, a função de divulgação mediática, de satisfação instantânea da imprensa." (PAIVA 2003: 302) e que os principais agentes do teatro apenas pontualmente reconheciam na fotografia a dimensão de um instrumento de trabalho criativo. Pois se o registo fotográfico do teatro é inquestionável, subsiste ainda a necessidade de questionar os termos dessa prática e aferir a consciência que os seus agentes têm 
do alcance da mesma e, sobretudo, avaliar a fotografia na dupla condição de documento e monumento.

\section{DEFINIÇÃO DO OBJECTO: FOTOGRAFIA DE TEATRO}

Por fotografia de teatro entende-se, inevitavelmente, o objecto fotográfico que tem como referente o teatro. Contudo, a abrangência do significante teatro e todo o universo semântico que o termo evoca - do espaço ao texto, do actor à representação - que permite quase tudo incluir, surge desde logo como um primeiro problema fazendo cair sobre o conceito o espectro da indefinição.

Assim, impõe-se uma aproximação ao objecto com vista à sua melhor definição. Distingam-se, antes de mais, as fotografias no teatro das fotografias de teatro para dizer que não importam a esta reflexão as primeiras, isto é, a utilização do medium fotografia na representação teatral. Dedica-se então este estudo às imagens produzidas a partir da cena, desde a sua construção até à sua divulgação. Tendo assim considerado as fotografias de teatro, identificam-se, com interesse para a análise, dois grupos de imagen ${ }^{1}$ que, por estabelecerem uma relação extremamente rica com a actividade teatral, são especialmente referidas ao falar-se de fotografia de teatro: fotografia de cena e retrato de actores.

\section{FOTOGRAFIA DE CENA}

Por fotografia de cena consideram-se as imagens produzidas a partir do processo de encenação ou do espectáculo à qual mantêm uma ligação expressa, por via dos adereços de cena, dos figurinos, das poses, ou outro elemento, podendo o registo fotográfico ser realizado tanto no espaço do teatro como no estúdio dos fotógrafos ou outros locais preparados para o efeito. Claudia Balk (BALK 2002) alude especificamente a este aspecto da construção do espaço da re-encenação que acontece no estúdio do fotógrafo e das suas consequências nas primeiras décadas da fotografia, alertando quer para a impossibilidade do registo fotográfico in loco, no palco, quer para a consequente intensificação de uma carga dramática por força da sua simulação.

Esta abordagem que a fotografia realiza do corpo do actor no contexto do teatro pode ser justificada em grande parte pelas circunstâncias tecnológicas da segunda metade do século XIX. Por um lado, os sistemas de iluminação são limitados, sendo responsáveis por uma luz de fraca intensidade que obrigavam a manter as luzes da sala acesas durante o espectáculo de forma a melhorar a visibilidade sobre o que se passava no palco. A novidade da electricidade iria alterar a situação, mas levaria ainda o seu tempo. Por exemplo, no caso português, o Teatro Nacional de S. Carlos - principal palco nacional naquele tempo - só em 22 de Maio de 1886 teria a instalação
1 Exclui-se a categoria de fotografia de espaços teatrais, pois embora se relacione com o conceito teatro, submete-se a outras questões paralelas. 
eléctrica definitiva (SILVA 2007: 17), sendo os restantes teatros alvo de campanhas posteriores ${ }^{2}$.

Por outro lado, a sensibilidade dos materiais fotográficos era ainda pouco adaptável à penumbra típica dos palcos e seria necessário aguardar pela industrialização da tecnologia da gelatina e do brometo de prata (Richard L. Maddox, em 1871), nos finais da década de 1880 e princípios da de 1890, para proporcionar ao fotógrafo a possibilidade do registo da cena nos palcos de teatro propriamente ditos.

Assim, propõe-se tipificar a fotografia de cena em dois grupos: fotografias que registam situações de cena; fotografias que resultam de simulações de cena.

Pelas razões referidas, só a partir da viragem do século XIX para o XX teremos tido "verdadeiros" registos de cena, com evidente alteração no modus operandi dos fotógrafos. Pode-se mesmo dizer, como se verificará mais adiante, que são imagens de outra tipologia cujas fronteiras são, por vezes, difíceis de definir - retratos de actor em personagem - que engrossam o volume de imagens relacionáveis com a cena no período de charneira entre os séculos XIX e xx.

\subsubsection{RETRATOS DE ACTOR}

A categoria retratos de actor é aquela em que se verifica maior número de imagens associadas ao teatro até às primeiras décadas do século xx. Surgem, praticamente desde o aparecimento da fotografia, em suportes estandardizados e muito variados (carte-de-visite, cabinet, victoria, promenade ou imperial, entre outros não uniformizados), além da sua publicação, mais tarde, em programas, nos jornais e na forma de postal ilustrado. Estes ganham particular destaque a partir da década de 90 do século XIX, em colecções de grande edição que garantiam o acesso do grande público aos retratos dos seus actores predilectos. Pode, no entanto, observar-se que nem todos os retratos partilham as mesmas características, podendo distinguir-se várias tipologias, dentro do grande grupo de retratos de actor. Em relação ao conteúdo destas imagens, afiguram-se como arrumos possíveis: o retrato à civil, o retrato do actor em personagem e o retrato de expressóes, sendo aqui tidos em consideração os dois últimos.

Os retratos de actor em personagem são imagens que remetem para o espaço da representação, sem, contudo, proporem obrigatoriamente uma leitura directa de uma peça ou cena. Estes retratos, normalmente com apenas um actor/personagem em foco, relacionam-se com o texto dramatúrgico e com a encenação por via do guarda-roupa e dos adereços - dimensão material mais objectiva -, mas muito, também, por via da pose que procura sintetizar o carácter e os traços mais vincados da personagem.
2 Sobre este assunto ver Filipe Figueiredo, O Insustentável Desejo Da Memória. Incursões Na Fotografia De Teatro Em Portugal (1868-1974), Dissertação de Doutoramento em Estudos Artísticos, ramo de Estudos de Teatro (Universidade de Lisboa, 2015). Cap. III.1, pp. 335-342. 
Já os retratos de expressão correspondem a registos de expressões faciais de vários actores realizados nos finais do século XIX e princípios do seguinte e resultam de uma associação entre o jogo teatral e a natureza humana de modo a criar ou reforçar a imagem da "versatilidade" do actor e transmitir a ideia das suas superiores qualidades. Contudo, algumas destas imagens não se relacionam com qualquer personagem, não existe qualquer identificação com uma representação teatral, mas o actor empresta o seu corpo com vista à materialização de expressões de valor universal, através de exercícios de expressão facial. Contudo, se é inequívoca a relação destas imagens com o teatro, estas não parecem esgotar-se nem na justificação de um gosto realista nem na atitude narcísica dos seus intérpretes.

\section{EM BUSCA DE UMA TEORIA DO OBJECTO FOTOGRAFIA DE TEATRO} ESPECIFICIDADES DA FOTOGRAFIA DE TEATRO

A questão que neste ponto ocorre formular é: que teoria(s) para compreender o espaço discursivo da fotografia de teatro? E a resposta não é nem simples nem inequívoca.

No contexto da imagem fotográfica, a fotografia de teatro coloca problemas específicos que se relacionam simultaneamente com três aspectos: por um lado, a ontologia do medium, por outro, as circunstâncias da representação teatral e, por fim, os termos da utilização das imagens e a expectativa que sobre elas recai. Em síntese, o questionamento inicial surge em torno da capacidade da fotografia para documentar a cena ou o universo teatral e as possibilidades da sua leitura. Como pode a imagem fotográfica documentar o acto performativo e operar a transferência da realidade referencial para a sua imagem? De que modo pode a fotografia de teatro constituir-se como objecto de memorização e documental e, simultaneamente, objecto discursivo autónomo?

Numa reflexão preliminar importa considerar que, antes de mais, estas imagens - fotografias - apresentam-se aos historiadores de teatro, ou àqueles que reflectem sobre esta prática, como valiosos testemunhos de uma realidade fugaz e irrecuperável que é a cena. Como disse Peter Buse, "[...] photographs in theatre criticism are the traces of an old relationship between photography and theatre." (BUSE 1997: 79) É, pois, difícil resistir à tentação do seu carácter epistémico, da sua natureza de apontador, deítica, fazendo acreditar na possibilidade de reconstituição da cena. Assim, como Molinari já antes questionou em relação a toda a iconografia, urge avaliar a verdadeira possibilidade de uma fotografia poder fixar a realidade da cena e responder a alguns dos mais óbvios desafios que aqui se colocam: transição da realidade tridimensional para o suporte a duas dimensões; transposição do tempo contí- 
nuo para o fragmento temporal; condicionamento sensorial da experiência, agora verificada exclusivamente através da visão; estabelecimento de uma equivalência cromática e de gama tonal; reconhecimento da estrutura representacional, que é o teatro, numa nova estrutura de representação (imagem da imagem).

Em função da complexa especificidade da fotografia de teatro, tanto a sua produção como a sua utilização e leitura sofreram várias abordagens ao longo dos tempos. Ora entendida como prática de fixação documental do evento efémero, ora como construção subjectiva de uma referência em torno daquele, a fotografia de teatro debateu-se sempre com o questionamento de um possível regime de significação.

\section{A FOTOGRAFIA DE TEATRO COMO PASSAPORTE DA MEMÓRIA}

A publicação, no pós-guerra, em França, do álbum Cents Ans de Théatre par la

Photographie dá conta do interesse que a fotografia despertava e do seu capital enquanto "activador" da memória. No prefácio do livro, Gérard Bauer dizia que: [Cet album] forme la première partie d'un vaste panorama, celui où cent ans de théâtre vont retrouver leur animation. II y aura suffi d'un choix: les photographies des comédiennes et des comédiens qui, de 1850 à nos jours, ont interprété avec éclat la tragédie, le drame, le mélodrame, la comédie et le vaudeville; et quelques témoignages contemporains sur ces artistes. (COURSAGET et al. 1947: 7).

Bauer defendia aqui um estatuto da imagem fotográfica como documento, mas simultaneamente como objecto afectivo. Referia que estas fotografias têm a capacidade de despertar as memórias de todos aqueles que, algum dia, sentiram a emoção de assistir a uma determinada representação teatral. Mas refere, igualmente, que, não ter presenciado o actor em palco e não conhecer as suas representações, não impede o observador de se deleitar com estas imagens:

[...] Mais cet album ne convie pas simplement au souvenir; et ce n'est pas son objet. [...] Et pourtant, quel plaisir nos éprouvons à les connaître, à les voir ici tels qu'ils ont ravis leur temps, dans un de leur rôles ou dans leur naturel! (COURSAGET et al. 1947:11)

Ainda a propósito do valor expressivo das imagens, Bauer refere que:

Quand, dans des années, il n'y aura plus aucun témoin de ces carrières, quand cette suite de portraits n'éveillera plus aucun souvenir vivant pour aucun homme, cet album n'en conservera pas moins un pouvoir 
d'enchantement. C'est qu'on n'évoque pas ce qui a composé le plaisir et l'émoi d'une quantité d'êtres sans faire naître encore le plaisir et l'émoi. (COURSAGET et al. 1947: 13)

É pois por essa ordem de ideias que deixa um claro elogio às imagens e aos seus autores:

[...] Comment ne pas louer à distance des photographes qui surent arrêter un moment et une apparence des êtres sans les priver de cette aura, dece rayon sans lequel nous ne possédons pas la totalité d'une créature! [...] Chacune des photographies de ce recueil livre vraiment un être, nous le livre dans ses réserves et dans ses excès. (COURSAGET et al. 1947: 12)

Apesar de reconhecerem o potencial estético e documental das fotografias, os autores desta obra atestam, fundamentalmente, o seu valor enquanto passaporte da memória, ou seja, como materiais evocativos da cena no palco, da sua representação, e da emoção do observador que a ela tenha, porventura, assistido. Ficaria, contudo, por esclarecer que grande parte das imagens publicadas neste álbum tampouco são verdadeiras fotografias de cena, por não terem sido realizadas no palco dos teatros ao tempo de qualquer umas das representações que nelas são evocadas, deixando por isso uma clara indefinição em relação ao estatuto destas imagens.

\section{A FOTOGRAFIA DE TEATRO COMO EXERCÍCIO TESTEMUNHAL E}

\section{DOCUMENTAL}

Entretanto, uma das mais conhecidas utilizações da fotografia associada ao universo da criação teatral era ensaiada com Brecht e a sua colaboradora Ruth Berlau na construção do que ficou conhecido como os modellbücher, cadernos de direcção que associam centenas de fotografias de cena, depois publicados em versões mais reduzidas e que eram, segundo a investigadora Meg Mumford, que dedicou parte dos seus estudos a Brecht,

"[...] both an educational tool and an innovative archive method - in an age prior to video documentation - that was designed to assist disseminations of Brecht's post-1945 methods of staging. Pioneered by Brecht's collaborator Ruth Berlau, each production report consisted of black and white photos and explanatory notes detailing Gestus-oriented approach to character as well as the Arrangement of the Fabel. (...) the model books proved a useful method for introducing and protecting his practice. (MUMFORD 2009: 174, Glossário) 
Ainda citando a mesma investigadora, cada modelbuch "contained a sequence of photos with captions, detailing significant gestures, positions, groupings and turning points in a particular production.", com o intuito de fixar a escrita cénica de Brecht através da tipificação de "[...] socially significant comportment, arrangements and tableaux." (MUMFORD 2009: 44)

Embora este exercício recue já ao início da década de 1930, por exemplo, com a peça Mann ist $\mathbf{M a n n ^ { 3 }}$, de 1931, só no fim da década seguinte são construídos os mais emblemáticos modellbücher, cada um composto por entre 600 a 800 fotografias. Peter Thomson e Glendyr Sacks defendem precisamente que é depois do regresso de Brecht à Europa e concretamente da sua adaptação de Antígona, muito fotografada por Berlau, que resulta "the first full-scale Modellbuch" (THOMSON and SACKs, 2006: 36): Antigonemodell, em 1948, seguindo-se, em 1949, um outro referente à encenação de Mãe coragem - Couragemodell (BRECHT 1994).

Meyer-Plantureux e Joel Anderson são dois dos autores que se têm dedicado a pesquisar acerca do valor da fotografia para Brecht com uma abordagem mais determinante. Embora o olhar de Brecht sobre este recurso possa ser algo contraditório, é inegável o papel crucial que este lhe atribui pela capacidade de, com o seu detalhe, interrogar o seu trabalho, levando-o a detectar, inclusivamente, erros de marcação e iluminação na encenação. É, de resto, sintomática a passagem que Meyer-Plantureux (MEYER-PLANTUREUX and DORT 1992: 28) resgata do diário de Brecht, de 1953, em que este refere ter a sua companheira Ruth Berlau realizado fotografias na véspera, que entretanto terão sido processadas de noite e vistas e analisadas nesse dia, o que confirma a natureza instrumental da sua utilização. Também nesse sentido, Anderson recorda como Brecht, embora criticasse as operações da fotografia, aderiu às "[...] possibilities of photography and the photographic in theatre [...]" (ANDERSON 2014: 68)

O fotógrafo que realiza o trabalho para Brecht assume um ponto fixo para a tomada de vistas das fotografias para os seus modellbücher, ainda que este possa ser alterado ao longo dos ensaios, de acordo com as cenas, de espectáculo para espectáculo e em função de outras condicionantes. Nos diversos modellbücher-Galilei, Antigone ou Couragemodell - , ainda que seja mais consistente nos dois últimos, é evidente a escolha de um ponto fixo da tomada de vistas, normalmente de ângulo aberto, seguido de algumas séries de planos mais fechados, no caso do Couragemodell, denominados de Details e Varianten. Os fotógrafos registam a cena com uma cadência acelerada - um dos tipos de Details referidos antes consistia precisamente em Details: Sequenzen -, gerando assim um registo que lembra facilmente uma visão "fílmica" da cena, o que parece 
consolidar a ideia de um valor documental da fotografia levado quase ao limite, com a convicção de poder constituir-se como um verdadeiro modelo.

Era o reconhecimento desse conceito de modelo e das possibilidades de fixação de uma escrita cénica que se pode entender nas palavras de Walter Benjamin, com quem Brecht partilhara algumas reflexões:

Assim, é decisivo que a produção tenha um carácter de modelo, capaz de, em primeiro lugar, levar outros produtores à produção e, em segundo lugar, pôr à sua disposição um aparelho melhorado. E esse aparelho é tanto melhor quanto mais consumidores levar à produção, numa palavra, quanto melhor for capaz de transformar os leitores ou espectadores em colaboradores. Já possuímos um modelo deste género, mas só lhe posso fazer aqui uma breve referência: trata-se do teatro épico de Brecht. (BENJAMIN 2006: 288)

Ora, é precisamente a encenação da peça Mãe coragem, de que se falou antes, agora apresentada pelo Berliner Ensemble, em Paris, em 1957, no ano a seguir à morte de Brecht, que irá suscitar uma interessante produção fotográfica, agora da responsabilidade do fotógrafo francês Roger Pic. As várias centenas de imagens que Pic captou parecem replicar o modelo usado por Brecht e os seus fotógrafos e assumir a fotografia com um estatuto testemunhal.

É precisamente sobre essas fotografias que Roland Barthes irá escrever o seu primeiro texto sobre fotografias de teatro no seu conhecido ensaio Sept photo-modèles de Mère Courage (BARTHES 1959, 1967). Se o carácter documental parecia estar consignado para este tipo de imagens, nem por isso elas deixaram de inquietar o espírito de Barthes, cujo questionamento da fotografia se verificaria seminal.

Apesar do título do ensaio estar centrado no objecto fotográfico, o conteúdo acaba por defraudar, de algum modo, as expectativas de encontrar ali uma reflexão focada no discurso das imagens. Na verdade, Barthes não se detém na análise de nenhuma das fotografias que selecciona. Ainda assim, na introdução ao seu ensaio, Barthes contextualiza estas fotografias, como sendo as imagens produzidas pelo "photo-journalist Pic" que terá usado uma teleobjectiva, graças ao que, segundo Barthes, produziu "[...] a true photographic history of Mother Courage." (BARTHEs 1967: 44).

Tal como Jim Carmody sinaliza, Barthes , neste ensaio, "[...] points to the camera's ability to capture detail for subsequent analysis." (CARMODY 1990:35), lamentando que não tivesse olhado as imagens de outras perspectivas:

He might, for instance, have used them as the starting point for a discussion of the new Myth of Brecht as it was emerging in Parisian 
cultural circles in the late 1950's [...]. Or he might well have examined Pic's photographs as examples of the discourse of photojournalism and theorized some of its recurrent tropes. Instead, he said nothing at all about Pic's photography, preferring to let it speak for itself. (CARMODY 1990: 35-36)

$\mathrm{Na}$ verdade, o interesse que Barthes manifesta por estas imagens reside na sua capacidade de produzir detalhes, isto é, tornar evidente um conjunto de pormenores que pelo seu destaque na imagem adquirem um protagonismo sobre o qual entende poder produzir as suas leituras. No caso em concreto, Barthes diz que "[...] Pic photographs throw light on the Brechtian notion of distancing [...]" (BARTHES 1967: 44). As sete fotografias de Pic que resgata do conjunto do levantamento servem para analisar como se verifica o efeito de distanciamento 4 na dramaturgia de Brecht, que para Barthes corresponde a "[...] to cut the circuit between the actor and his own pathos, but it is also, and essentially, to re-establish a new circuit between the role and the argument; it is, for the actor, to give meaning to the play, and no longer to himselfin the play." (BARTHES 1967: 44).

Barthes diz, a propósito da utilização das fotografias de Pic no seu artigo, "I want to to show how the detail of the gesture has a political meaning [...]", e, assim, propõe uma peça em que o sentido "[...] is no longer the actor's truth, but the political relationship of situations." (BARTHES 1967: 45)

Apesar do interesse de Barthes nestas imagens de Roger Pic, não é claro o estatuto que elas assumem, entre o seu carácter documental e monumental. Num texto mais recente em torno das mesmas imagens de Pic, a investigadora Maria Giulia Dondero questiona o papel que Barthes atribuía à fotografia como exaltadora de detalhes. Ao contrário de Barthes, Dondero analisa as imagens que convoca. É olhando para as imagens de Pic, colocando-as lado a lado, e tomando de empréstimo as palavras de Ugo Volli, em que este diz que "[...] many theatre photographers challenge [...] the work of the director ou scenographer." (DONDERO 2008: 44), que a investigadora Dondero defende que a fotografia altera a essência do acto performativo:

Only photos let Kattrin, Mother Courage's mute daughter, claim her role; this did not happen in the performance, where the character Kattrin was completely dominated by the actress Hélène Weigel, who played Mother Courage. In the stills taken by Pic, Hélène Weigel's strong scenic presence diminishes, and that proves that drama is an art of moving bodies and energy expressed in action, whereas photography shows bodies as fixed points and frozen gestures. (DONDERO 2008: 44-45)
4 Também dito efeito de distanciamento ou $v$-effect para se referir à expressão alemã Verfremdungseffekt. 
A mesma autora reconhece na fotografia, além do seu efeito alterador, a capacidade de gerar um efeito de introspecção, que poderia aqui ser entendido como uma forma de absorção, no sentido em que Fried se lhe refere (FRIED 1980, 2008):

By stopping movement, theatre photography also succeeds in portraying introspection, a power rarely found in the visual arts. The easiest way for performing thought is, of course, soliloquy; thanks to its framing that arrests and extracts the character from the ongoing action, photography can be considered an autonomous generator of soliloquies. (DONDERO 2008: 45)

Ainda assim, Dondero reconhece no ritmo implacável e de grande fôlego do trabalho de Roger Pic, sobre Mãe Coragem, qualidades que lhe permitem produzir uma amostra das várias fases do acto performativo, levando-a a afirmar que "Pic's shots intend to be the statement of a statement." (DONDERO 2008: 51). Mas Pic não procura essa afirmação através de imagens estáveis e transparentes. Dondero verifica que momentos de explosão emocional são representados nas fotografias através de efeitos de desfocagem e arrastamentos, sendo esses aspectos que não são visíveis para os espectadores: "Clearly, then, Pic's photographs are not meant to be transparent recordings: rather, they dig and seep." (DONDERO 2008: 51). Não obstante o intuito com que são convocadas estas imagens pelos seus autores / utilizadores / leitores, importa reconhecer que elas vão mais além do que o suposto carácter testemunhal e documental. Como salienta ainda Dondero, "Photography captures what lies between the stage and the strategies of theatre in order to disclose the very apparatus of theatre. Theatre photography represents an epiphany of the productive performance that "bleeds" from the fiction" (DONDERO 2008: 55), ou seja, a fotografia enquanto dispositivo tem a capacidade de, em grau variado, denunciar os mecanismos de construção do exercício teatral, seja através de um enquadramento aberto que integre o espaço do edifício teatral ou as zonas inacessíveis ao público, como os bastidores, ou ângulos de vista que o público não pode perspectivar a partir do seu lugar, seja através de planos fechados sobre pormenores, e é nesta medida que elas devem ser interrogadas.

\section{A FOTOGRAFIA DE TEATRO E AS SUAS INDEFINIÇÕES. REPRESENTAR}

\section{A REPRESENTAÇÃO}

Num importante artigo, publicado em 1997, Peter Buse levanta algumas questões importantes em relação ao modo de ler as fotografias de teatro e ao seu valor. Buse começava por se debater com a ausência de discussão teórica das 
fotografias de teatro e sinalizava o modo pouco criterioso com que as fotografias eram usadas no contexto da crítica teatral. Por uma lado, reconhecia que: Amongst academics - and not only art historians - it is currently an acceptable, and even approved, practice to turn to the visual as an area ofinquiry, on the condition that they carry out informed and sophisticated readings of the pictures they present. In line with disciplinary requirements visual pleasure is tempered, qualified and modified by scrutiny and analysis.

Mas, por outro lado, não podia deixar de lamentar que:

Nothing of the sort happens in the case of photographs in theatre criticism. Not only is no attempt made to read these pictures as photographs, no reference is made to their putative content: they are left unread. (BUSE 1997: 77)

Segundo este autor, a ausência de leitura do objecto resultava do (des)entendimento generalizado que recaía sobre a fotografia e os seus equívocos. Buse reconhecia, porém, razões que justificavam esta incompreensão e defendia que raramente se confrontavam as fotografias enquanto objecto, porque:

[...] since photographs are generally looked through, a viewing practice encouraged not only by the camera's singular capacity to generate "effects of the real," but by the photographic apparatus's adoption of the picture frame, a convention inherited from the 15th century Albertian perspective, and one which only serves to reinforce the impression that photos are windows onto something else. (BUSE 1997: 78)

Dizia ainda que as fotografias de teatro, fruto dessa condição, não suscitavam a observação, do tipo, "I am looking AT a photograph." (BUSE 1997: 78) e que é essa indefinição do seu estatuto enquanto imagens a grande responsável pelo modo como estas são incompreendidas. Não é possível questionar a sua função e a sua presença, pois "[...] while their status as photographs is not highlighted, neither are they simply illustrative and subordinate to the text." (BUSE 1997: 78).

Este é talvez um dos pontos mais pertinentes do seu ensaio quando, perante os equívocos que as fotografias de teatro suscitam, Buse procura responder à questão: "If the photographs from plays belong to neither the instrumental nor the illustrative orders, then what purpose do they serve?" (BUSE 1997: 89). Ora, Buse justifica, então, o interesse das fotografias na capacidade que elas encerram de fazer presente uma matéria ausente, independentemente do modo como o fazem, convocando para esta ideia, tanto o "isto-foi" barthesiano, quanto as 
reflexões que Christian Metz alinha em Photography as Fetish, consagrando à sua ausência um valor fetichista, já que se a "Photography is a cut inside the referent, it cuts off a piece of it, a fragment, a part object." (apud BUSE 1997: 89)

Neste ponto, o contributo recente de John Kulvicki (2011) apresenta-se bastante pertinente ao evidenciar que no caso das fotografias de teatro nos encontramos perante dois níveis de representação distintos: o da representação performativa e o da representação fotográfica. Consequentemente, importa reconhecer não apenas a especificidade da forma, como também da matéria que anima essa forma, ou seja, a natureza da representação teatral.

Partindo dos seus estudos de abordagem estruturalista da imagem (2003, 2006), Kulvicki procura definir elementos estruturais destes dois níveis de representação para os confrontar. A primeira evidência verifica-se ao nível da sua natureza representacional: de alguma maneira, ambas as imagens mimetizam. Se já antes se aludiu a esta propriedade da fotografia, agora Kulvicki assegura também que igual premissa se mantém para o teatro.

Theater performances themselves are representational: they are about situations portrayed by the actors and set. Indeed, one could certainly have a theater performance that is about other theater performances, in whole or in part. (KULVICKI 2011:43)

Neste seu estatuto de representações miméticas, fotografia e teatro partilham duas qualidades decisivas que as aproximam: por um lado, a transparência e, por outro, a expressividade. No entanto, Kulvicki acautela:

Despite being transparent in the technical sense mentioned earlier, therefore, images are not mere windows onto their objects. We have to understand the kind of image we encounter in order to see its object in it. (KULVICKI 2011: 52-53)

Dessa análise, no caso das fotografias de teatro, resulta a compreensão de algumas diferenças que marcam igualmente a sua estrutura de representação: a fotografia não tem marcações, enquanto o teatro tem; a fotografia não tem um guião e o teatro tem; a fotografia é um objecto, o teatro é um evento com uma dimensão performativa.

Distinguidas as diferenças estruturais dos dois dispositivos, deve assumir-se que se trata de duas imagens diferentes. Sendo o teatro uma representação com uma natureza performativa, ao contrário das fotografias; as imagens de teatro nunca irão partilhar os aspectos performativos do teatro. Reconhece-se, assim, a distinção necessária entre signo e referente, o que vai no sentido preciso das ideias de McIver Lopes (2007) quando alerta para a 
promiscuidade entre as formas do objecto e as formas da fotografia do objecto, da qual poderiam resultar juízos erróneos. Kulvicki enuncia mesmo o problema do seguinte modo:

Sometimes is it because of what is represented that some artifact is expressive, sometimes an artifact manages to be expressive despite what it represents, and sometimes the artifact is expressive completely independently of what it represents. (KULVICKI 2011: 54)

Dito de outra forma, perante a fotografia de teatro, é imperioso ser capaz de destrinçar a expressividade da imagem daquela outra expressividade inerente à representação teatral.

Ter algum conhecimento sobre o evento performativo e o seu referente textual, o fotógrafo e as características do seu trabalho, assim como as condicionantes do mesmo, serão por certo ferramentas determinantes para tratar as imagens de uma determinada representação. Estas condicionantes são extremamente variáveis e obrigam, por exemplo, a considerar aspectos atinentes à escolha do fotógrafo num regime de contratação, às funções expectadas para a imagem, à visão do fotógrafo acerca da representação referencial, a partir de quadrantes interpretativos variados - económicos, sociológicos, culturais, perceptivos e fenomenológicos.

Já em 1996, Jean-Maria Schaeffer, a este propósito, questionava:

Como distinguir entre o que pertence à imagem e o que pertence propriamente ao real, quando se está diante de uma imagem cuja especificidade consiste em ser apreendida como um registo do real? Como diferenciar, por exemplo, nas maravilhosas fotos botânicas de Blossfeldt, o que pertence à tomada de vista e o que faz parte da riqueza da natureza? (SCHAEFFER 1996: 142-43)

Considerando a expressividade como um factor determinante na representação, Kulvicki definiu duas formas de atingir, através da imagem fotográfica, a expressividade da representação teatral:

[...] through dispassionate images that nevertheless represent an expressive performance, or through images that are themselves expressive in the way the performance was. (KULVICKI 2011: 54-55)

De acordo com esta análise de Kulvicki, aquilo que se pode encontrar nas fotografias de teatro, teoricamente, não será mais do que a sua expressividade, ainda que esta adquira aqui um sentido representacional. 
Será pois este o entendimento do encenador Jorge Silva Melo (2010) que desacredita a transparência inexpressiva do medium, do seu estatuto de documento, capaz de atingir a representação e defende que a fotografia de teatro não serve para fazer a sua história. No seu entender, a fotografia assume um valor metonímico - a assunção do todo pela parte. Por isso, defende que "A tarefa do fotógrafo de teatro é tentar descobrir a verdade do actor dentro da cena, ou seja, dentro da proposta de mentira que ali está. Encontrar isso é extraordinário!"5

Esta afirmação vai ao encontro da ideia de Kulvicki quando se refere à dimensão representacional que assumem as características expressivas das imagens fotográficas ao referirem-se à expressividade do acto performativo. Diz ainda Kulvicki que:

By being expressive in the way the performance was, such images replicate and thereby represent the expressivity of the performance. Such images need not even represent the performance in any great detail. They can be vague-mere gesture drawings-just so that they are expressive of what the performance expresses, be it an emotion, a state of mind, or something else. (KULVICKI 2011: 55).

Para concluir, o que importa numa abordagem à fotografia de teatro recai inexoravelmente nesta distância que vai entre a imagem e o seu referente - o evento teatral -, tarefa particularmente dificultada quer pela efemeridade deste quer pela extrema complexidade ontológica do medium. A fotografia, pode dizer-se, assume assim um papel heurístico, uma vez que não sendo capaz de produzir um análogo é, contudo, capaz de indagar, questionar a memória do evento performativo através da sua estrutura representacional. E é nessa medida que pode ser dito que a grande responsabilidade pela complexidade da compreensão deste objecto assenta precisamente na presença de vários níveis de representação, numa autêntica mise en abyme. É com base nessa condição que pode igualmente ser dito que a fotografia é uma instrumento perverso, precisamente pela sua capacidade de gerar a expectativa de uma experiência análoga àquela vivida perante o real. A fotografia preenche os requisitos para ser a mais poderosa das ferramentas, aquela que é capaz por excelência de mentir, iludir com os dados do real. E essa capacidade de gerar equívocos assume tanto maior alcance quanto maior for a aparente semelhança da cena representada com a sua imagem, numa perspectiva mimética.

É precisamente essa a condição que Victor Burgin no seu ensaio Looking at Photographs, de 1982, considera fundamental: "The effect of representation [...] requires that the stage of the represented [...] meet the stage of the representing in a "seamless join"”. (BURGIN 1982:150)
5 Extraído de gravação áudio de uma mesa redonda realizada no âmbito do encontro Teatro e Imagens (Centro de Estudos de Teatro / Faculdade de Letras da Universidade de Lisboa, 5 e 6 de Fevereiro de 2010). 
Apesar de na maioria dos casos acontecer de modo quase instantâneo e imperceptível, na verdade, diz ainda Victor Burgin "Once we have discovered what the depicted object is [...] the photograph is instantly transformed for us - no longer a confusing conglomerate of light and dark tones, of uncertain edges and ambivalent volumes, it now shows a "thing" wich we invest with a fully identity, a being." (BURGIN 1982:146-47) Esse é precisamente o terreno pantanoso em que assentam tantas vezes as mais profundas convicções de se poder rever o evento performativo na sua representação fotográfica.

Certo é que a fotografia de teatro exige uma acção hermenêutica vigorosa que contemple, além do problema da representação e da expressividade, outros factores que foram aqui apenas aflorados - das estratégias da produção da imagem à problemática do seu consumo - com vista ao seu verdadeiro entendimento global.

\section{REFERÊNCIAS BIBLIOGRÁFICAS}

ANDERSON, Joel (2014), Theatre and Photography (London: Palgrave Macmillan).

BALK, Claudia (2002), '“Theatricality" and photography - iconographic similarities in nineteenth-century role portraits: postures, costumes and spatial situations', in Christopher Balme, Robert Erenstein, and Cesare Molinari (eds.), European Theatre Iconography Conference (Roma: Bulzoni Editore). BARTHES, Roland (1959), 'Sept photo-modèles de Mère Courage', Théâtre Populaire, 35 ( $3^{\circ}$ tr.).

(1967), 'Seven Photo Models of "Mother Courage" ', TDR, 12 (1, Bertolt Brecht, Autumn), 44-55

BATE, David (2009), Photography: The Key Concepts (Oxford / New York: Berg). BENJAMIN, Walter (2006), 'O autor como produtor', A Modernidade (Lisboa: Assírio \& Alvim), 271-93.

BRECHT, Bertolt (1994), Grosse kommentierte Berliner und Frankfurter Ausgabe. Schriften 5. Theatermodelle. "Katzgraben" - Notate 1953. Aufbau einer Rolle / Laughtons Galilei. Antigonemodell 1948. Couragemodell 1949. (Bertolt Brecht, Werke; Berlin: Suhrkamp Verlag).

BURGIN, Victor (1982), 'Looking at Photographs', in Victor Burgin (ed.), Thinking photography (London: MacMillan Press), 130-37.

BUSE, Peter (1997), 'Stage Remains: Theatre Criticism and the Photographic Archive', Journal of Dramatic Theory and Criticism, XII (1).

CARMODY, Jim (1990), 'Reading Scenic Writing: Barthes, Brecht, and Theatre Photography', Journal of Dramatic Theory and Criticism, North America, V (1). COURSAGET, René, GAUTHIER, Maximilien, and BAUER, Gérard (Préface) (1947), Cent ans de Théatre par la Photographie (Cent Ans; Paris: Editions L'Image). 
DONDERO, Maria Giulia (2008), 'Photography as a Witness of Theatre', RS·SI - Recherches sémiotiques / Semiotic Inquiry, 28 (1-2), 43-57.

FIGUEIREDO, Filipe (2015), 'O insustentável desejo da memória. Incursões na fotografia de teatro em Portugal (1868-1974)', Dissertação de Doutoramento em Estudos Artísticos, ramo de Estudos de Teatro (Universidade de Lisboa). FRIED, Michael (1980), Absorption and theatricality: painting and beholder in the age of Diderot (Berkeley: University of California Press) xvii, 249 p. (2008), Why photography matters as art as never before (New Haven: Yale University Press) ix, 409 p.

KULVICKI, John (2003), 'Image structure', The Journal of Aesthetics and Art Criticism, 61 (4), 323-40.

_ (2006), On images - their structure and content (Oxford: Clarendon Press). (2011), 'Imaging Performance', in Maria João BRILHANTE, Paula MAGALHÃES, and Filipe FIGUEIREDO (eds.), Imagens de uma Ausência. Modos de (re) conhecimento do teatro através da imagem (Lisboa: Colibri / Centro de Estudos de Teatro - Faculdade de Letras da Universidade de Lisboa), 43-57. LOPES, Dominic McIver (2007), 'The aesthetics of Photographic Transparency (2003)', in Alex Neill and Aaron Ridley (ed.), Arguing about art, contemporary philosophical debates ( $3^{\mathrm{a}}$ edn.; London \& New York: Routledge). MEYER-PLANTUREUX, Chantal and DORT, Bernard (introd.) (1992), La photographie de théâtre ou la mémoire de l'éphémère (Paris: Éditions Paris Audiovisuel).

MUMFORD, Meg (2009), Bertolt Brecht (New York: Routledge).

PAIVA, Susana (2003), 'Duas revelações frontais e uma determinada fixação nas costas, antecedidas por breve introdução. Paper presented at the $\mathbf{O}$ Homem de Costas: o corpo no teatro, cinema, fotografia e artes plásticas (2002)', in Centro de Estudos de Teatro - Associação Portuguesa de Críticos de Teatro (ed.), Teatro em Debate(s) (Lisboa: Livros Horizonte), 301-04.

SCHAEFFER, Jean-Marie (1996), A Imagem Precaria: Sobre o Dispositivo Fotografico (São Paulo: Papirus Editora).

SILVA, Catarina Branco Leite da (2007), 'Estudo da Eficiência Luminosa e Energética do Sistema de Iluminação Pública da Cidade do Porto', (Faculdade de Engenharia da Universidade do Porto). 